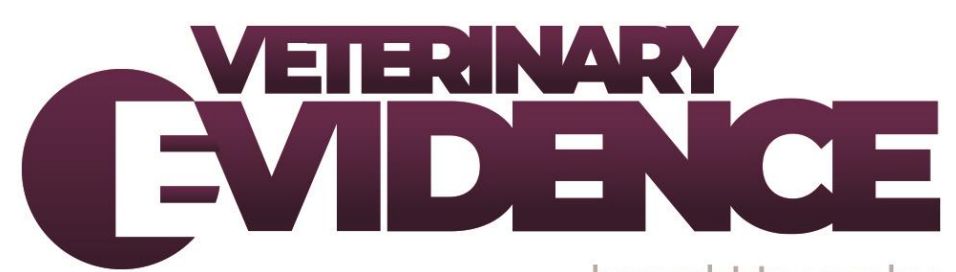

\title{
A critical appraisal of the literature exploring the surgical treatment of degenerative lumbosacral stenosis in dogs
}

Sara Silva DVM, MSc, MRCVS ${ }^{{ }^{*}}$

L. Miguel Carreira PhD, MSc, DTO, Pst-Grd, DMD, DVMS ${ }^{1}$

Telmo Nunes DVM, MSC ${ }^{1}$

François Saulnier-Troff DVM, DesChirPA, DipECVS, MRCVS ${ }^{2}$

\footnotetext{
${ }^{1}$ Faculty of Veterinary Medicine of the University of Lisbon, Av. Universidade Técnica, 1300-477 Lisboa, Portugal, 0000-0002-3897-499X

${ }^{2}$ Veterinary Emergency and Specialty Hospital, 2-14 Rochdale Road, SINGAPORE 535815.

* Corresponding Author (sara silva7@hotmail.com)
}

ISSN:

Published:

in:

DOI:

Reviewed by:
2396-9776

17 Apr 2020

Vol 5, Issue 2

10.18849/VE.V512.287

Frank Steffen (Dipl. ECVN) and Malcolm Ness (BVetMed, CertSAO,FRCVS, ECVS) 
Objective: To critically appraise the literature exploring the surgical treatment of degenerative lumbosacral stenosis in dogs.

Background: Several surgical procedures to treat degenerative lumbosacral stenosis (DLSS) in the dog have been reported, however, definitive criteria for surgical technique preference are currently lacking (1).

Evidentiary value and methods: A critical appraisal tool that examined the conduct and reporting of studies on the results of surgical treatment of DLSS was designed and, after a systematic search and screening of the literature, a critical appraisal was performed in 20 papers.

Results: Results showed that $18 / 20$ studies included did not clearly report inclusion and exclusion criteria and in 14/20 it was unclear whether consecutive inclusion of participants was applied. 19/20 studies reported age, breed, and sex of the participants, and 13/20 did not report duration and prevalence of clinical signs. In 13/20 studies, it was considered that the condition was not measured in a standard and reliable way. Objective outcome measures were used in $7 / 20$ studies.

Conclusion and application: The results demonstrate that there is room for improvement in the conduct and reporting quality of case series so that rigorous data can be generated and analysed, to inform research design, guide clinical practice, and improve veterinary healthcare delivery.

\section{INTRODUCTION}

DLSS is the compression of the cauda equina caused by protrusion of supportive tissues into the vertebral canal (2). Young adult, male, and large-breed dogs seem to be predisposed to this condition, although it can also affect cats $(1,3-7)$. Surgical treatment is often performed, particularly when medical treatment fails to provide adequate relief of clinical signs or when neurological deficits are too severe for medical management alone $(1,4,8-10)$. Although several surgical procedures have been reported, definitive criteria for surgical technique preference are currently lacking (1).

Literature reporting the results of the surgical treatment of DLSS in dogs is mainly composed of case reports and case series. While new and more advanced research methods arise, paving the way for evidence-based medicine, evidence provided from case series and case reports has lost its scientific significance, and its reliability, and therefore its clinical acceptance has been questioned $(11,12)$. The concepts of "case series" and "case reports" are, however, not well defined in the literature. Therefore, the definitions proposed by AbuZidan, Abbas \& Hefny (13), in which it is suggested that case series should have more than four participants, will be used throughout this paper.

Critical appraisal is the process of systematically examining research evidence to judge its trustworthiness, its value and relevance in a particular context (14). Poorly designed and conducted studies can compromise the integrity of the research process and mislead healthcare decision-making at all levels $(15,16)$. Some areas of veterinary medicine have a large body of high ranking evidence, while many others only have poor and low quality forms of evidence $(17,18)$. Therefore, a critical appraisal of available research is essential to make informed decisions in clinical practice. Concern has been raised about the need for better designed and reported clinical trials to assess the outcomes of surgical treatment of DLSS (19-21), which further emphasises the importance of a critical appraisal of published studies on the topic. The main objective of this study was to critically appraise the literature reporting the results of surgical treatment of DLSS; to identify gaps in current 
knowledge and ensure there is justification for future research on the subject; and to propose study characteristics that would enrich the conduct and reporting of these studies.

METHODS \& MATERIALS

\section{Literature search}

The literature search was performed in July 2016 and included the use of three electronic databases: PubMed, Web of Science (1900-present), and Google Scholar (1900-present). Electronic search in PubMed and Web of Science was performed in English and in Google Scholar in Portuguese. Each search had similar components searched as keywords and medical subject headings joined using Boolean operators (Annex 1). The electronic search was complemented with a hand-search in references of review articles and book chapters by: Bagley (22), Sjöström (23), Sharp \& Wheeler (1), Meij \& Bergknut (20) and Lanz \& Rossmeisl (7). This was updated with articles published between 2016 and 2019.

\section{Inclusion and exclusion criteria}

Case series or higher ranking evidence was included. For inclusion, papers had to be in vivo studies which reported surgical outcomes of DLSS, published in peer reviewed journals, with the full-text available in English or Portuguese. Articles also had to have at least five participants and concern domestic dogs. Articles which reported only lumbosacral traumatic lesions, discospondylitis, osteochondrosis, or neoplasia, were excluded.

\section{Screening process}

All electronic references were imported into Endnote and all duplicates were removed. Articles that did not meet the inclusion criteria or met the exclusion criteria were assessed first by their title and secondly by their abstract, and were removed. The full text was then obtained, if possible. Articles were accessed through the internet if access was available from the Faculty of Veterinary Medicine of the University of Lisbon. If an article was unavailable online or at the Faculty of Veterinary Medicine Library, an attempt to retrieve it by electronic contact with the publishing journal and authors was made.

\section{Critical appraisal}

A critical appraisal tool for case series combining the JBI critical appraisal checklists for case reports and case series $(24,25)$, the case report guidelines (26) and the three-minute critical appraisal checklist (27) was designed. The critical appraisal tool examines the conduct and reporting of the participant selection process, participant demographics and clinical information, condition measurement, and outcome assessment (Annex 2).

Clear criteria were considered when inclusion and exclusion criteria were described in detail in the case series. An unclear reporting of inclusion or exclusion criteria was considered when one or both of them were not reported. Criteria for inclusion or exclusion of participants for each study were also recorded. Consecutive inclusion of participants was considered when the authors clearly reported that all the patients presented in a certain time period were included in the study. If it was not mentioned that all patients presented in a specific time period were included, this was considered as "unclear". Clear reporting of participant demographics was considered when age, breed and sex were reported for all included animals. Clear reporting of clinical information of the participants was considered if prevalence and duration of clinical signs were stated. Measurement of the condition was considered reliable if all animals were diagnosed with the same measure which assured its repeatability. If there was evidence of a lack of standardisation in condition measurement between participants, the answer was registered as "no". In lack of a validated diagnostic methodology for the diagnosis of DLSS, all diagnostic methods that can provide a diagnosis for DLSS were considered valid. When radiography was performed alone, and no confirmation of diagnosis was performed at surgery, the methodology was considered invalid. Ancillary diagnostic investigations and pain elicitation manoeuvers used for the diagnosis of DLSS were recorded. A clear reporting of outcomes or follow-up results was considered when presence or absence of postsurgical clinical signs was fully described, as well as how and when follow-up was performed and measured. The reporting and measurement methodology for outcome assessment was registered, as well as study follow-up rates. 
A summary of key criteria to answer the critical appraisal tool questions is presented in Table 1.

The results of the critical appraisal were then collated into a summary table and analysed.

\section{RESULTS}

\section{Search and screening process}

143 papers were initially identified. Following screening, 123 studies were excluded on title and abstract basis and 20 papers fulfilled the inclusion criteria.

\section{Critical appraisal}

The results of the close-ended questions of the critical appraisals are summarised in Table 2. Table 3 summarises the answers to the open-ended questions.

$2 / 20$ studies included in the critical appraisal clearly reported the criteria for inclusion and exclusion of participants in the case series. $8 / 20$ studies did not clearly mention any selection criteria. Out of all studies that reported exclusion criteria (9), 4/9 excluded animals with lumbosacral disease other than DLSS (discospondylitis, neoplasia, traumatic injuries) or concurrent orthopaedic problems. One study excluded only participants with concurrent orthopaedic problems. Although $9 / 20$ studies clearly reported exclusion criteria, $5 / 20$ reported inclusion criteria.

$6 / 20$ included studies clearly reported consecutive inclusion of participants while in 14/20 it was unclear if the inclusion of participants was made in a consecutive way.

$19 / 20$ studies clearly reported age, breed, and sex, of the participants. Weight (28-31) and level of activity (4, 32 ) were additionally reported in some studies. $13 / 20$ included studies did not clearly report duration and presence of clinical signs among the participants.

Measurement of the condition (DLSS) was considered standardised and reliable in $7 / 20$ appraised studies. When considering time of publication, particularly studies from the last 16 years, we can observe that 10/20 had a diagnostic methodology considered standardised and reliable. 
Table 1 - Key criteria to answer each question of the critical appraisal tool.

\begin{tabular}{ll}
\hline Question & Criteria \\
\hline $\begin{array}{l}\text { 1 - Were there criteria for inclusion and } \\
\text { exclusion in the case series? }\end{array}$ & $\begin{array}{l}\text { Inclusion and exclusion criteria were } \\
\text { described in detail }\end{array}$ \\
\hline $\begin{array}{l}\text { 2 - Did the case series have consecutive } \\
\text { inclusion of participants? }\end{array}$ & $\begin{array}{l}\text { All patients presented in a specific time } \\
\text { period were included in the study }\end{array}$ \\
\hline $\begin{array}{l}\text { 3 - Was there clear reporting of the } \\
\text { demographics of the participants in the study? }\end{array}$ & $\begin{array}{l}\text { Age, breed, and sex of all participants was } \\
\text { clearly reported }\end{array}$ \\
\hline $\begin{array}{l}\text { 4- Was there clear reporting of clinical } \\
\text { information of the participants? }\end{array}$ & $\begin{array}{l}\text { Duration and prevalence of clinical signs } \\
\text { was fully reported }\end{array}$ \\
\hline $\begin{array}{l}\text { 5 - Was the condition measured in a standard } \\
\text { and reliable way for all participants included } \\
\text { in the case series? }\end{array}$ & $\begin{array}{l}\text { The condition was measured with the same } \\
\text { instruments and in a reproducible way for all } \\
\text { participants }\end{array}$ \\
\hline $\begin{array}{l}\text { 6 - Were valid methods used for identification } \\
\text { of the condition for all participants included in } \\
\text { the case series? }\end{array}$ & $\begin{array}{l}\text { A methodology that can provide a diagnosis } \\
\text { of DLSS was used }\end{array}$ \\
\hline $\begin{array}{l}\text { 7 - Were the outcomes or follow-up results of } \\
\text { cases clearly reported? }\end{array}$ & $\begin{array}{l}\text { Presence or absence of postsurgical clinical } \\
\text { signs was fully described, as well as how } \\
\text { and when it was assessed }\end{array}$ \\
\hline
\end{tabular}

The majority of studies (19/20) used valid methods for the identification of the disease. However, one study (33) did not. Radiography was used in $15 / 20$ of studies. Although CT and MRI were used, respectively, in $8 / 20$ and $12 / 20$ included studies, when considering only studies published in the last 16 years, those values are severely altered. In that time period, it was observed that 5/10 and 9/10 of studies used CT and MRI, respectively, as a diagnostic tool.

In 17/20 studies, it was considered that outcome assessment or follow-up results of cases were adequately performed. In all included studies, outcomes were measured as presence or absence of postsurgical signs. In $10 / 20$ of these, postsurgical signs were measured by physical examination of the participants after discharge. Out of the studies reporting outcomes as postsurgical signs and in which there was no report of a postdischarge physical examination, 3/6 did not report how outcomes were assessed and 2/6 used owner questionnaires. Owner assessment was performed in 12/20 included studies. In 7/12 of these, a standardised questionnaire was used. However, not all studies using this outcome assessment measure provided a detailed description of the content of the questionnaires. In the remaining studies, the method for owner assessment was not clearly specified. Objective outcome measures, which include diagnostic imaging techniques, Force plate analysis (FPA), or performance in standardised exercises, were used in $7 / 20$ included studies. Out of 
these, 2/7 used FPA, 5/7 used diagnostic imaging techniques (radiography or CT), and 1/7 used performance in standardised exercises.

In 9/20 included studies, the follow-up rate was reported or was possible to calculate from available data at standard periods for at least one outcome measure. The mean follow-up rate in these studies was $93 \%$. Although follow-up was performed in standard times for each study, this did not happen between studies, so the follow-up rate was calculated at the time of the first outcome measurement. In 11/20 included studies, the follow-up rate was reported or was possible to calculate from available data, however, participants had different times of follow-up for all outcome measures. The mean post-discharge follow-up rate in these studies was $94 \%$. The minimum time of outcome assessment between all included studies ranged from immediately post-surgery to 1.5 years. When looking at studies which assessed long-term outcome (more than 1 year) in standard periods (4/20), the mean follow-up rate is as low as $37 \%$.

Table $\mathbf{2}$ - Summary of appraisal of the 20 studies which met the inclusion criteria (close-ended questions)

\begin{tabular}{|c|c|c|c|c|c|c|c|}
\hline Article & & & al ap & tool c & & & \\
\hline & $\overline{1}$ & 2 & 3 & $\overline{4}$ & 5 & $\overline{6}$ & $\overline{7}$ \\
\hline Oliver et al. (44) & Unclear & Yes & Yes & No & No & Yes & No \\
\hline $\begin{array}{l}\text { Tarvin \& Prata } \\
\text { (45) }\end{array}$ & Unclear & Unclear & Yes & Yes & No & Yes & No \\
\hline Denny et al. (35) & Unclear & Unclear & Yes & No & No & Yes & No \\
\hline $\begin{array}{l}\text { Slocum \& Devine } \\
\text { (33) }\end{array}$ & Unclear & Unclear & No & No & Yes & No & Yes \\
\hline Watt (36) & Unclear & Yes & Yes & No & No & Yes & Yes \\
\hline Ness (40) & Unclear & Yes & Yes & No & No & Yes & Yes \\
\hline $\begin{array}{l}\text { Danielsson \& } \\
\text { Sjöström (4) }\end{array}$ & Unclear & Unclear & Yes & Yes & No & Yes & Yes \\
\hline Jones et al. (42) & Unclear & Unclear & Yes & No & Yes & Yes & Yes \\
\hline De Risio et al. (32) & Yes & Unclear & Yes & Yes & No & Yes & Yes \\
\hline Linn et al. (5) & Unclear & Unclear & Yes & No & No & Yes & Yes \\
\hline Steffen et al. (46) & Unclear & Unclear & Yes & No & No & Yes & Yes \\
\hline $\begin{array}{l}\text { Gödde \& Steffen } \\
(28)\end{array}$ & Unclear & Unclear & Yes & Yes & Yes & Yes & Yes \\
\hline $\begin{array}{l}\text { Suwankong et al. } \\
\text { (10) }\end{array}$ & Unclear & Unclear & Yes & Yes & No & Yes & Yes \\
\hline $\begin{array}{l}\text { Suwankong et al. } \\
\text { (47) }\end{array}$ & Unclear & Unclear & Yes & Yes & No & Yes & Yes \\
\hline
\end{tabular}




\begin{tabular}{lccccccc} 
Hankin et al. (48) & Unclear & Yes & Yes & No & No & Yes & Yes \\
\hline Golini et al. (49) & Unclear & Yes & Yes & No & Yes & Yes & Yes \\
\hline Tellegen et al. (29) & Unclear & Unclear & Yes & No & No & Yes & Yes \\
\hline Rapp et al. (30) & Unclear & Unclear & Yes & No & Yes & Yes & Yes \\
\hline Gomes et al. (50) & Yes & Unclear & Yes & Yes & Yes & Yes & Yes \\
\hline Steffen et al. (31) & Unclear & Yes & Yes & No & Yes & Yes & Yes \\
\hline
\end{tabular}

Table 3 - Summary of appraisal of the 20 studies which met the inclusion criteria (open-ended questions)

\begin{tabular}{|c|c|c|c|c|}
\hline \multirow[t]{2}{*}{ Article } & \multicolumn{3}{|c|}{ Critical appraisal tool question* } & \multirow[b]{2}{*}{ Follow-up rate } \\
\hline & Criteria & Methods & Outcomes & \\
\hline Oliver et al. (44) & Exclusion & radiography, TSV, EMG & PS & $\begin{array}{l}77 \% \text { at different } \\
\text { follow-up periods }\end{array}$ \\
\hline $\begin{array}{l}\text { Tarvin \& Prata } \\
(45)\end{array}$ & Unclear & radiography, TSV, myelography & PS & $\begin{array}{l}100 \% \text { at different } \\
\text { follow-up periods }\end{array}$ \\
\hline Denny et al. (35) & Unclear & radiography & PS & $\begin{array}{l}100 \% \text { at different } \\
\text { follow-up periods }\end{array}$ \\
\hline $\begin{array}{l}\text { Slocum \& Devine } \\
\text { (33) }\end{array}$ & Unclear & radiography & PS by PE, radiography & $100 \%$ at 2 months \\
\hline Watt (36) & Unclear & $\begin{array}{l}\text { radiography, myelography, } \\
\text { epidurography }\end{array}$ & PS by PE, OA & $100 \%$ at 14 days \\
\hline Ness $(40)$ & Unclear & $\begin{array}{l}\text { radiography, myelography, } \\
\text { epidurography }\end{array}$ & PS by OA & $\begin{array}{l}94 \% \text { at different } \\
\text { follow-up periods }\end{array}$ \\
\hline $\begin{array}{l}\text { Danielsson \& } \\
\text { Sjöström (4) }\end{array}$ & Exclusion & $\begin{array}{l}\text { radiography, myelography } \\
\text { epidurography, discography }\end{array}$ & PS by PE, OA, OQ & $\begin{array}{l}100 \% \text { at different } \\
\text { follow-up periods }\end{array}$ \\
\hline Jones et al. (42) & Exclusion & radiography, $\mathrm{CT}$, and MRI & PS by PSE, CT & $100 \%$ at 6 months \\
\hline De Risio et al. (32) & $\begin{array}{l}\text { Exclusion } \\
\text { and } \\
\text { inclusion }\end{array}$ & $\begin{array}{l}\text { radiography, EMG, myelography } \\
\text { epidurography, discography, CT, } \\
\text { MRI }\end{array}$ & PS by PE, OA, OQ & $\begin{array}{l}100 \% \text { at different } \\
\text { follow-up periods }\end{array}$ \\
\hline Linn et al. (5) & Exclusion & $\begin{array}{l}\text { radiography, EMG, } \\
\text { myelography, epidurography, } \\
\text { discography, CT, MRI }\end{array}$ & PS by PE & $\begin{array}{l}100 \% \text { at different } \\
\text { follow-up periods }\end{array}$ \\
\hline Steffen et al. (46) & Unclear & $\begin{array}{l}\text { radiography, myelography, } \\
\text { discography, MRI }\end{array}$ & PS by PE, OA & $\begin{array}{l}100 \% \text { at different } \\
\text { follow-up periods }\end{array}$ \\
\hline $\begin{array}{l}\text { Gödde \& Steffen } \\
(28)\end{array}$ & Exclusion & MRI & PS by PE, OA & $100 \%$ at 6 months \\
\hline $\begin{array}{l}\text { Suwankong et al. } \\
\text { (10) }\end{array}$ & Exclusion & radiography, CT, MRI, FPA & PS by OA, OQ, FPA & $100 \%$ at 6 months \\
\hline
\end{tabular}




\begin{tabular}{|c|c|c|c|c|}
\hline $\begin{array}{l}\text { Suwankong et al. } \\
\text { (47) }\end{array}$ & Exclusion & $\begin{array}{l}\text { radiography, myelography, } \\
\text { epidurography, discography, CT, } \\
\text { MRI }\end{array}$ & PS by PE, OA, OQ & $\begin{array}{l}67 \% \text { at different } \\
\text { follow-up periods }\end{array}$ \\
\hline Hankin et al. (48) & Unclear & radiography, myelography, CT & $\begin{array}{l}\text { PS by PE, radiography, } \\
\text { OA, OQ }\end{array}$ & $81 \%$ at 6 weeks \\
\hline Golini et al.(49) & Inclusion & MRI & PS by PE, CT & $\begin{array}{l}100 \% \text { at different } \\
\text { follow-up periods }\end{array}$ \\
\hline Tellegen et al. (29) & Unclear & radiography, CT, MRI, FPA & $\begin{array}{l}\text { PS by OA, OQ, } \\
\text { radiography, CT, FPA }\end{array}$ & $58 \%$ at 4 to 6 weeks \\
\hline Rapp et al. (30) & Inclusion & CT, MRI & PS by PE, CT, MRI & $\begin{array}{l}100 \% \text { at different } \\
\text { follow-up periods }\end{array}$ \\
\hline Gomes et al. (50) & $\begin{array}{l}\text { Exclusion } \\
\text { and } \\
\text { Inclusion }\end{array}$ & MRI & PS by PE, OA & $100 \%$ at 6 weeks \\
\hline Steffen et al. (31) & Inclusion & MRI & PS by PE, OQ, MRI & $100 \%$ at 10 months \\
\hline
\end{tabular}

Key to table:

TSV - transosseous vertebral venography

EMG - electromyography

$\mathrm{CT}$ - computed tomography

$\mathrm{MRI}$ - magnetic resonance imaging

FPA - force plate analysis

PS - postsurgical signs

$\mathrm{PE}$ - physical examination

OA - owner assessment

PSE - performance in standardised exercises

$\mathrm{OQ}$ - owner questionnaire

\section{DISCUSSION}

Clear criteria for inclusion and exclusion of participants in a case series are essential for readers to be able to apply them to their patients and help define those who have received the intervention and those who should not receive it (34). In order to be able to compare case series, clinical inclusion and exclusion criteria need accurate and clear reporting (21). Many different terms are used in the literature to report lumbosacral disease, and it involves diverse pathological events $(4,7,23,35,36)$, which further highlights the importance of clear inclusion and exclusion criteria of participants in case series which report surgical treatment of this complex disease.

Case series are, due to their non-randomised nature, very prone to different kinds and risks of bias, especially selection bias (37). Selection bias occurs not only when the selection of patients is not random but also if not all patients presenting with a relevant condition are included in order of entry consecutively (38). Therefore, consecutive inclusion of participants is highly relevant in case series. It increases their reliability and credibility, and reduces selection bias $(25,34)$. 
A full description of participant demographic information is essential to characterise the generalisability of research findings in a study and to make comparisons $(25,39)$. Age, breed, and sex, of the participants were considered to be highly relevant because they provide valuable information on disease predisposition and prognostic factors. In studies on dogs with DLSS these seem to be particularly important due to the apparent predisposition of young adult, male, and large-breed dogs, especially German Shepherd dogs $(4,5,7)$. A high level of activity has been reported as a risk factor for the development of DLSS and may play a role in patient prognosis $(1,5,19,40-42)$, which highlights its importance in the reporting of patient demographics in case series. Weight may also play a part in DLSS and on patient prognosis, so it is also relevant to report (19). It is essential that all clinical information of the participants is clearly and fully reported $(25,34,43)$. Lack of this further hampers a full and in-depth characterisation of the disease and jeopardises the investigation of causality between the chronicity of clinical signs and patient prognosis.

Duration of clinical signs was considered a criterion for clear reporting because although some studies have found no correlation between duration of clinical signs and patient prognosis (4), some clinical signs of chronic progression have been associated with a negative prognostic value for postsurgical outcome $(5,32)$. Prevalence of clinical signs was also analysed because it is important to fully characterise the disease severity of all participants and the generalisability of the treatment results $(38,51)$.

It is important that the method of measurement of the condition is the same for all patients (standard) and produces repeatable and reproducible results (reliable) $(25,38,51)$. Studies from the last 16 years appear to have a more standardised and reliable way of measuring the participants' condition, which may reveal a trend towards a more cautious condition measurement in studies on the surgical treatment of DLSS over time. Standardisation and reliability should, however, not be mistaken for study quality. For example, in the study by Slocum \& Devine (33), the diagnosis relied on the signalment, physical examination, and radiographic findings of all included animals. Therefore, it was considered that this study was measured in a standard and reliable way. In the study by Suwankong et al. (10), diagnosis relied on signalment, physical examination, radiography, and CT or MRI findings of included animals. Because not all included animals were diagnosed using the same methods, this study was not considered to have a standardised methodology. Now, unlike conventional radiography, $\mathrm{CT}$ and $\mathrm{MRI}$ have proven to be sensitive and specific detectors of cauda equina compression in $\operatorname{dogs}(1,2,20,41,52,53)$. Although in one study (33) the measurement of the condition was performed in a standard and more reliable way, the other (10) used far more accurate and advanced diagnostic imaging techniques, factors that make their quality incommensurable.

It is essential that a diagnosis is made based on existing definitions or diagnostic criteria. Outcome assessment validity depends on the use of validated condition measurement tools $(25,34)$. In the study by Slocum \& Devine (33) radiography was used alone as a diagnostic imaging tool and surgical confirmation of DLSS was not reported. That may be because distraction-fusion was the employed surgical technique, which may not allow for surgical detection of cauda equina compression. Although normal radiographic findings do not exclude DLSS (53-56), the majority of studies used radiography as a diagnostic method, which further emphasises that it is commonly used in patients in which there is suspicion of DLSS. This may be because it is a widely available procedure, when compared to CT or MRI, which can aid in the exclusion of diseases other than DLSS that may mimic its clinical signs $(20,23,54,56-58)$. The majority of studies from the last 16 years used CT or MRI as a method for identification of the condition. This further supports the premise that these advanced diagnostic imaging techniques have become increasingly available and valuable tools both in the diagnosis of DLSS and in veterinary medicine $(2,20,53)$. In a review article by Jeffery $(21)$, concern was raised about the quality of the reporting of pain evocation methods used in studies on patients with DLSS. Therefore, pain evocation was also analysed in the 20 included studies. It was concluded that $95 \%$ of studies reported how lumbosacral pain was elicited, which demonstrates that the reporting quality of that measure is significant. 
It is extremely important that the full clinical condition of the participants after an intervention or treatment is clearly reported $(25,43)$ in order to characterise their success. So that outcomes of different interventions can be compared and generalisation is possible, reporting of how and when follow-up was performed and measured is equally important. Although some studies which did not report postsurgical complications were classified as having a clear reporting methodology of follow-up results, this feature is also relevant in case series. The diagnosis of DLSS should be based on, among other factors, the physical examination of the animal $(1,7,20)$. Therefore, the postsurgical assessment should also rely on physical examination by an experienced professional. When owner questionnaires are used, detailed reporting of their content is desirable. Although subjective methods such as owner questionnaires and veterinary lameness scores have been validated and are useful outcome measures, they are a source of assessor bias. Therefore, a caregiver placebo effect by both veterinarians and pet owners should be considered when interpreting reports of response to treatment (59, $60)$. However, there are currently no validated and specific owner questionnaires or veterinary lameness scores for outcome assessment of animals treated for DLSS, which poses as a limitation. Objective outcome measures are valuable in improving the understanding of treatment effects in research studies, and provide results that are comparable between studies (21). Although they are valuable tools to assess screw position and condition and bone fusion in distraction-fusion techniques $(29,49)$ significant association between imaging studies and postoperative outcomes has not been identified (42). Furthermore, there is also no apparent correlation between imaging findings and disease severity $(2,61)$.

Loss of patients to follow-up is important because it influences the validity of the treatment or study protocol (27). It was challenging to assess follow-up rates of many studies due to unclear reporting of follow-up at different times. For studies in which follow-up was performed at standard times, the rate was calculated at time of first outcome measurement. Presentation of this data as a mean rate for the first outcome measure alone, and not the entire time of follow-up assessment, results in an overestimation of the follow-up rate, which must be considered when interpreting this data. Conversely, because only some of the studies included in this category used standard periods of outcome measurement alone, this value could also be underestimated for studies which also reported outcomes at different times. The follow-up rate of studies reporting outcome assessment at different times for all outcome measures proved to be higher than the follow-up rate of studies in which outcome assessment was performed at standard periods. However, comparison between these two types of studies is debatable. The minimum time of outcome assessment between studies presented as a wide range of values, which further emphasises the heterogeneity of included studies. Although the hardship for clear reporting of follow-up rates and periods for retrospective studies with a high number of participants is comprehensible, that method assures that comparison between treatment results and generalisation of findings are possible, and that a full interpretation of treatment results is feasible.

\section{LIMITATIONS}

This critical appraisal was hampered by several limitations. Firstly, a validated and specific critical appraisal tool for case series was not identified in the literature. In order to overcome this limitation, three critical appraisal checklists and a guideline for case reports were combined, and a critical appraisal tool was designed, in order to conduct this study. Secondly, many different terms are used to describe lumbosacral disease and the several surgical techniques described to treat it, which posed as limitations throughout the study, particularly when establishing a search strategy. An attempt was made to overcome this limitation by using a wide range of search terms in the search process. The authors of the study were familiar with research on the surgical treatment of DLSS, therefore blinding of the screening process was not possible. Furthermore, inclusion and exclusion criteria for studies, as well as criteria for answering the critical appraisal checklist, may 
have been influenced by previous knowledge of the literature. Finally, although an attempt was made to establish clear and objective criteria for answering the questions proposed in the designed critical appraisal tool, its subjective nature poses as a limitation.

CONCLUSIONS

Validation of a critical appraisal tool for case series would greatly benefit and enrich the critical appraisal of such studies. Although there are several limitations to the execution of randomised controlled trials or other studies representing higher level of evidence to ascertain which treatment option is the best for patients with DLSS, this study has demonstrated that there is room for improvement of the conduct and reporting quality of case series, so that rigorous data can be generated and analysed, to inform research design, guide clinical practice, and improve veterinary healthcare delivery (26). However, we must also consider that even the most robust, prospectively conducted, and clearly reported case series have limitations which make the quality of the evidence they provide incomparable to that provided by well-constructed randomised controlled trials (62).

PROPOSED STUDY CHARACTERISTICS

Reporting guidelines improve the completeness of published scientific reports, so grounding the manuscript of a case series on a validated guideline such as the case report (CARE) guidelines, is advised (26). A case series on the surgical treatment of DLSS should begin with a clear title. The words "case series" should appear on it, along with the intervention of greatest interest so that a precocious identification of the topic and goals of a study can be performed by reviewers and veterinary healthcare professionals $(26,43)$. Although the decision to include keywords on a paper may depend on specific journal requirements, it has been advised. The use of medical subject headings is preferred (12). Clear clinical inclusion and exclusion criteria should be accurately reported, because they allow case series to be compared against one another. One of the main features that limit criteria for participant selection is the retrospective nature of the literature on the topic. The establishment of prospective studies would overcome this limitation $(21,60)$. Consecutive inclusion of participants ought to be conducted and clearly reported because it increases case series reliability and credibility, and reduces selection bias $(25,34)$. Patient demographic information, such as age, breed, sex, level of activity, and weight, should be fully reported, so that predisposition and risk factors may be assessed (25, 39). A complete report of the clinical information and diagnostic methodology used in all participants in a case series, mainly the findings of physical, neurologic, and orthopaedic examinations, is advised. In addition to prevalence of clinical signs, duration also seems to be an important measure $(5,32,38,51)$. Standardisation of diagnostic methodologies increases study reliability, therefore it is recommended $(25,38,51)$. The manoeuvre for pain elicitation should equally be described. Advanced diagnostic imaging techniques are becoming increasingly available and are valuable tools to assess cauda equina compression, so their use has been recommended, when available $(2,20,21)$. Description of which criteria the diagnosis was based on helps define if the results of a study are reproducible (25). The complete treatment protocol should be clearly described, so that it can be understood by the reader and replicable $(24,43)$. The outcomes and follow-up results also need to be fully reported and measured, especially how outcome measurement was conducted and which type of tools were used by the assessors. Objective outcome measures, ideally validated, such as FPA and performance in standardised exercises have been advised (21). However, concurrent use of standardised and validated subjective outcome measures such as owner questionnaires and veterinary lameness scores could also prove to be useful, providing that a caregiver placebo effect is accounted for (59). Blinding of outcome assessment could be used to enrich the conduct of outcome measurement, limiting systematic bias (21). Standardisation of outcome measurement would, similarly to standardisation of 
diagnostic methodologies, increase study reliability, so it is recommended (17). This should include outcome assessment with the same outcome measures and at the same time post surgically for all participants. Loss of participants to follow-up influences study protocol validity, so it should be limited and clearly reported, if it occurs (27). Because not all reported surgical techniques have assessed long-term postoperative outcome of DLSS treatment, a follow-up of a year or more is recommended based on reports of recurrence of clinical signs in patients which underwent surgical treatment for $\operatorname{DLSS}(5,32)$.

CONFLICT OF INTEREST

The authors declare no conflicts of interest.

REFERENCES

1. Sharp, N.J.H. \& Wheeler SJ. Lumbosacral Disease. In: Sharp, N.J.H. \& Wheeler, S.J., editors. Small Animal Spinal Disorders: Diagnosis and Surgery. 2nd ed. Philadelphia: Elsevier Mosby; 2005. p. 181210.

2. Dewey, C.W. Surgery of the Cauda Equina. In: Fossum, T.W., Dewey, C.W., Horn, C.V. Johnson, A.L., MacPhail, C.M., Radlinsky, M.G., Schulz, K.S. \& Willard, M.D., editor. Surgery of the Cauda Equina. 4th ed. Missouri: Elsevier Mosby; 2013. p. 1529-44.

3. Hurov, L. Laminectomy for treatment of cauda equina syndrome in a cat. Journal American Veterinary Medical Association. 1985. 186:504-5.

4. Danielsson, F. \& Sjöström, L. Surgical treatment of degenerative lumbosacral stenosis in dogs. Veterinary Surgery. 1999;28(2):91-8. DOI: http://dx.doi.org/10.1053/jvet.1999.0091

5. Linn, L.L., Bartels, K.E., Rochat, M.C., Payton, M.E. \& Moore, G.E. Lumbosacral Stenosis in 29 Military Working Dogs: Epidemiologic Findings and Outcome after Surgical Intervention (1990-1999). Veterinary Surgery. 2003. 32(1):21-9. DOI: https://doi.org/10.1053/ivet.2003.50001

6. Harris, J.E. \& Dhupa, S. Lumbosacral Intervertebral Disk Disease in Six Cats. Journal American Animal Hospital Association. 2008. 44:109-15. DOI: http://dx.doi.org/10.5326/0440109

7. Lanz, O.I. \& Rossmeisl Jr., J.H. Lumbosacral Spine. In: Tobias, K.M., Johnston, S.A., editors. Veterinary Surgery: Small Animal. Missouri: Elsevier Mosby; 2012. p. 476-86.

8. Slocum, B. \& Devine, T. L7-S1 Fixation-Fusion Technique for Cauda Equina Syndrome. In: Bojrab, M.J., Ellison, G.W. \& Slocum, B., editors. Current Techniques in Small Animal Surgery. 4th ed. Maryland: Williams \& Wilkins; 1998. p. 861-4.

9. De Risio, L., Thomas, W.B. \& Sharp, N.J. Degenerative lumbosacral stenosis. Veterinary Clinic North America Small Animal Practice. 2000. 30(1):111-132, vi. DOI: https://doi.org/10.1016/S01955616(00)50005-9

10. Suwankong, N., Meij, B.P., Van Klaveren, N.J., Van Wees, A.M.T.C., Meijer, E., Van Den Brom, W.E. \& Hazewinkel, H.A.W. Assessment of decompressive surgery in dogs with degenerative lumbosacral stenosis using force plate analysis and questionnaires. Veterinary Surgery. 2007. 36(5):423-31. DOI: http://dx.doi.org/10.1111/j.1532-950X.2007.00288.x

11. Nissen, T. \& Wynn, R. The clinical case report : a review of its merits and limitations. BMC Research Notes. 2014. 1-7. DOI: http://dx.doi.org/10.1186/1756-0500-7-264

12. Garg, R., Lakhan, S.E. \& Dhanasekaran, A.K. How to review a case report. Journal of Medical Case Reports. 2016. 1-5. DOI: http://dx.doi.org/10.1186/s13256-016-0853-3

13. Abu-zidan, F.M., Abbas, A.K. \& Hefny, A.F. Clinical " case series": a concept analysis. African Health Sciences. 2012;4:557-62. DOI: http://dx.doi.org/10.4314/ahs.v12i4.25

14. Burls, A. What is critical appraisal? 2009.

15. Moher, D., Schulz, K.F., Altman, D.G. \& Group, C. CONSORT statement The CONSORT statement: revised recommendations for improving the quality of reports of parallel-group randomised trials. 
Lancet. 2001. 357:1191-4. DOI: http://dx.doi.org/10.1016/S0140-6736(00)04337-3

16. Maskhar, R., Emmanuel, P., Mishra, S., Patel, S., Naik, E. \& Kumar, A. Critical appraisal skills are essential to informed decision-making. Indian Journal of Sexually Transmitted Diseases and AIDS. 2009. 30(2):112-9. DOI: http://dx.doi.org/10.4103/0253-7184.62770

17. Schulz, K.S., Cook, J.L., Kapatkin, A.S. \& Brown, D.C. Evidence-Based Surgery: Time for Change. Veterinary Surgery. 2006. 35:697-9.

18. Dean, R. How to read a paper and appraise the evidence. In Practice. 2013. 35(May):282-6. DOI: http://dx.doi.org/10.1136/inp.f1760

19. Worth, A.J. \& Hartman, A. Degenerative lumbosacral stenosis in working dogs : Current concepts and review. New Zealand Veterinary Journal. $2009.27(6): 319-30$. DOI: https://doi.org/10.1080/00480169.2009.64719

20. Meij, B.P. \& Bergknut, N. Degenerative Lumbosacral Stenosis in Dogs. Veterinry Clinics of North America: Small Animal Practice. 2010.20 40(5):983-1009. DOI: http://dx.doi.org/10.1016/i.cvsm.2010.05.006

21. Jeffery, N.D., Barker, A. \& Harcourt-brown, T. What progress has been made in the understanding and treatment of degenerative lumbosacral stenosis in dogs during the past 30 years? The Veterinary Journal. 2014. 201(1):9-14. DOI: http://dx.doi.org/10.1016/j.tvjl.2014.04.018

22. Bagley, R.S. Surgical Stabilization of the Lumbosacral Joint. In: Slatter D, editor. Textbook of Small Animal Surgery. 3rd ed. Philadelphia: Saunders; 2003. p. 1238-43.

23. Sjöström, L. Degenerative lumbosacral stenosis: Surgical Decompression. In: Slatter, D., editor. Textbook of Small Animal Surgery. 3rd ed. Philadelphia: Saunders; 2003. p. 1227-37.

24. The Joanna Briggs Institute. JBI critical appraisal checklist for case reports. In: Joanna Briggs Institute Reviewer's Manual: 2016 edition. Australia: The Joanna Briggs Institute; 2016.

25. The Joanna Briggs Institute. JBI critical appraisal checklist for case series. In: Joanna Briggs Institute Reviewer's Manual: 2016 edition. Australia: The Joanna Briggs Institute; 2016.

26. Gagnier, J.J., Kienle, G., Altman, D.G., Moher, D., Sox, H., Riley, D. \& The CARE Group. The CARE guidelines: consensus-based clinical case report guideline development. Jouranl of Clinical Epidemiology. 2014. 67:46-51. DOI: http://dx.doi.org/10.1016/j.jclinepi.2013.08.003

27. Chan, K. \& Bhandari, M. Three-minute critical appraisal of a case series article. Indian Journal of Orthopaedics. 2011. 45(2):103-4. DOI: http://dx.doi.org/10.4103/0019-5413.77126

28. Gödde, T. \& Steffen, F. Surgical Treatment of Lumbosacral Foraminal Stenosis Using a Lateral Approach in Twenty Dogs with Degenerative Lumbosacral Stenosis. Veterinary Surgery. 2007. 36(May):705-13. DOI: http://dx.doi.org/10.1111/i.1532-950X.2007.00324.x

29. Tellegen, A.R., Willems, N., Tryfonidou, M.A. \& Meij, B.P. Pedicle screw-rod fixation : a feasible treatment for dogs with severe degenerative lumbosacral stenosis. BMC Veterinary Research. 2015. 11:1-13. DOI: http://dx.doi.org/10.1186/s12917-015-0614-3

30. Rapp, M., Ley, C.J., Hansson, K. \& Sjöström, L. Postoperative computed tomography and low-field magnetic resonance imaging findings in dogs with degenerative lumbosacral stenosis treated by dorsal laminectomy. Veterinary and Comparative Orthopaedics and Traumatology. 2017;30:143-52. DOI: http://dx.doi.org/10.3415/VCOT-16-06-0096

31. Steffen F, Bertolo A, Affentranger R, Ferguson S.J. \& Stoyanov, J. Treatment of Naturally Degenerated Canine Lumbosacral Intervertebral Discs with Autologous Mesenchymal Stromal Cells and Collagen Microcarriers: A Prospective Clinical Study. Cell Transplant. 2019. 28(2):201-11. DOI: http://dx.doi.org/10.1177/0963689718815459

32. De Risio, L., Sharp, N.J., Olby, N.J., Muñana, K.R. \& Thomas, W.B. Predictors of outcome after dorsal decompressive laminectomy for degenerative lumbosacral stenosis in dogs: 69 cases (1987-1997). The Journal of the American Medical Association. $2001.219: 624-8$. DOI: http://dx.doi.org/10.2460/javma.2001.219.624

33. Slocum, B. \& Devine, T. L7-S1 fixation-fusion for treatment of cauda equina compression in the dog. Journal of the American Veterinary Medical Association. 1986. 188(1):31-5.

34. Albrecht, J., Werth, V.P. \& Bigby, M. The role of case reports in evidence-based practice, with 
suggestions for improving their reporting. Journal of the American Academy of Dermatology. 2009. 60(3):412-8. DOI: http://dx.doi.org/10.1016/j.jaad.2008.10.023

35. Denny, H.R., Gibbs, C. \& Holt, P.E. The diagnosis and treatment of cauda equina lesions in the dog. Journal of Small Animal Practice. 1982. 23(8):425-43. DOI: http://dx.doi.org/10.1111/i.17485827.1982.tb03772.x

36. Watt, P.R. Degenerative lumbosacral stenosis in 18 dogs. Journal of Small Animal Practice. 1991. 32(3):125-34. DOI: http://dx.doi.org/10.1111/i.1748-5827.1991.tb00527.x

37. Green, S., Higgins, J.P.T., Anderson, P., Clarke, M., Mulrow, C.D. \& Oxman, A.D. Introduction. In: Haggins, J.P.T. \& Green, S., editors. Cochrane Handbook for Systematic Reviews of Interventions: Version 510. The Cochrane Collaboration; 2011.

38. Lijmer, J.G., Mol, B.W., Heisterkamp, S., Bonsel, G.J., Prins, M.H., Van Der Meulen, J.H.P. \& Bossuyt, P.M.M. Empirical evidence of design-related bias in studies of diagnostic tests. The Journal of the $\begin{array}{llll}\text { American Medical } & \text { Association. }\end{array}$ DOI: http://dx.doi.org/10.1001/jama.282.11.1061

39. Sifers, S.K., Puddy, R.W., Warren, J.S. \& Roberts, M.C. Reporting of demographics, methodology, and ethical procedures in journals in pediatric and child psychology. Journal of Pediatric Psychology. 2002. 27(1):19-25. DOI: http://dx.doi.org/10.1093/ipepsy/27.1.19

40. Ness, M.G. Degenerative lumbosacral stenosis in the dog : Areview of 30 cases. Journal of Small Animal Practice. 1994. 185-90. DOI: http://dx.doi.org/10.1111/j.1748-5827.1994.tb01683.x

41. Jones, J.C., Sorjonen, D.C., Simpson, S.T., Coates, J.R., Lenz, S.D., Hathcock, J.D., Agee, M.W. \& Bartels, J.E. Comparison Between Computed Tomographic and Surgical Findings in Nine Large-breed Dogs with Lumbosacral Stenosis. Veterinary Radiology \& Ultrasound. $1996.37(4): 247-56$. DOI: http://dx.doi.org/10.1111/i.1740-8261.1996.tb01226.x

42. Jones, J.C., Banfield, C.M. \& Ward, D.L. Association between postoperative outcome and results of magnetic resonance imaging and computed tomography in working dogs with degenerative lumbosacral stenosis. Journal of the American Veterinary Medical Association. 2000. 216(11):1769-74. DOI: http://dx.doi.org/10.2460/javma.2000.216.1769

43. Green, B.N. \& Johnson CD. How to write a case report for publication. Journal of Chiropractic Medicine. 2006. 5(2):72-82. DOI: http://dx.doi.org/10.1016/S0899-3467(07)60137-2

44. Oliver, J.E., Selcer, R.R. \& Simpson, S. Cauda equina compression from lumbosacral malarticulation and malformation in the dog. Journal of the American Veterinary Medical Association. 1978. 173(2):20713.

45. Tarvin, G. \& Prata, R.G. Lumbosacral stenosis in dogs. Journal of the American Veterinary Medical Association. 1980. 177(2):154-9.

46. Steffen, F., Berger, M. \& Morgan, J.P. Asymmetrical, transitional, lumbosacral vertebral segments in six dogs: a characteristic spinal syndrome. Journal of the American Animal Hospital Association. 2004. 40:338-44. DOI: http://dx.doi.org/10.5326/0400338

47. Suwankong, N., Meij, B.P., Voorhout, G., De Boer, A.H. \& Hazewinkel, H.A.W. Review and retrospective analysis of degenerative lumbosacral stenosis in 156 dogs treated by dorsal laminectomy. Veterinary and Comparative Orthopaedics and Traumatology. 2008. 21(3):285-93.

48. Hankin, E.J., Jerram, R.M., Walker, A.M., King, M.D. \& Warman, C.G.A. Transarticular Facet Screw Stabilization and Dorsal Laminectomy in 26 Dogs with Degenerative Lumbosacral Stenosis with Instability. Veterinary Surgery. 2012. 41(5):611-9. DOI: http://dx.doi.org/10.1111/j.1532950X.2012.01002.x

49. Golini, L., Kircher, P.R., Lewis, F.I. \& Steffen, F. Transarticular fixation with cortical screws combined with dorsal laminectomy and partial discectomy as surgical treatment of degenerative lumbosacral stenosis in 17 dogs: Clinical and computed tomography follow-up. Veterinary Surgery. 2014. 43(4):405-13. DOI: http://dx.doi.org/10.1111/i.1532-950X.2014.12117.x

50. Gomes, S.A., Lowrie, M. \& Targett, M. Long-term outcome following lateral foraminotomy as treatment for canine degenerative lumbosacral stenosis. Veterinary Record. 2018. 183:1-6. DOI: http://dx.doi.org/10.1136/vr.104741 
51. Jaeschke, R., Guyatt, G.H. \& Sackett, D.L. Users' guides to the medical literature, III. How to use an article about a diagnostic test, B. What are the results and will they help me in caring for my patients? The Journal of the American Medical Association. 2014. 271(9):703-7. DOI: http://dx.doi.org/ 10.1001/iama.1994.03510330081039

52. Jones, J.C., Cartee, R.E. \& Bartels, J.E. Computed tomographic anatomy of the canine lumbosacral spine. Veterinary Radiology \& Ultrasound. 1995;36(2):91-9. DOI: http://dx.doi.org/10.1111/j.17408261.1995.tb00223.x

53. Ramirez, O. \& Thral, I.D.E. A Review of Imaging Techniques for Canine Cauda Equina Syndrome. Veterinary Radiology \& Ultrasound. 1998. 39(4):283-96. DOI: https://doi.org/10.1111/i.17408261.1998.tb01608.x

54. Morgan, J.P. \& Bailey, C.S. Cauda equina syndrome in the dog: radiographic evaluation. Journal of Small Animal Practice. 1990. 31:69-77. DOI: http://dx.doi.org/10.1111/i.1748-5827.1990.tb00724.x

55. Scharf, G., Steffen, F., Grünenfelder, F., Morgan, J.P. \& Flückiger, M. The Lumbosacral Junction in Working German Shepherd Dogs - Neurological and Radiological Evaluation. Journal of Veterinary Medical Series A. 2004. 32:27-32. DOI: http://dx.doi.org/10.1111/i.1439-0442.2004.00587.x

56. Steffen, F., Hunold, K., Scharf, G. \& Roos, M. A follow-up study of neurologic and radiographic findings in working German Shepherd Dogs with and without degenerative lumbosacral stenosis. Journal of the American Veterinary Medical Association. $2007.231(10): 1529-33$. DOI: http://dx.doi.org/10.2460/javma.231.10.1529

57. Mattoon, J.S. \& Koblik, P.D. Quantitative Survey Radiographic Evaluation of the Lumbosacral Spine of Normal Dogs and Dogs with Degenerative Lumbosacral Stenosis. Veterinary Radiology \& Ultrasound. 1993. 34(3):194-206. DOI: http://dx.doi.org/10.1111/j.1740-8261.1993.tb02005.x

58. McKee, M. Differential diagnosis of cauda equina syndrome. In Practice. 2007. 15:243-50. DOI: http://dx.doi.org/10.1136/inpract.15.5.243

59. Conzemius, M.G. \& Evans, R.B. Caregiver placebo effect for dogs with lameness from osteoarthritis. Journal of the American Veterinary Medical Association. 2012. 241(10):1314-9. DOI: http://dx.doi.org/10.2460/javma.241.10.1314

60. Costa, R.C. Degenerative lumbosacral stenosis in dogs: Will we see progress in the next 30 years ? The Veterinary Journal. 2014. 202(2):201-2. DOI: http://dx.doi.org/10.1016/j.tvjl.2014.09.011

61. Mayhew, P.D., Kapatkin, A.S., Wortman, J.A. \& Vite, C.H. Association of Cauda Equina Compression on Magnetic Resonance Images and Clinical Signs in Dogs With Degenerative Lumbosacral Stenosis. Journal of the American Animal Hospital Association. 2002. 38:555-62. DOI: http://dx.doi.org/10.5326/0380555

62. Kooistra, B., Dijkman, B., Ta, E. \& Bhandari, M. How to Design a Good Case Series. The Journal of Bone \& Joint Surgery. 2009. 91:21-6. DOI: http://dx.doi.org/10.2106/JBJS.H.01573

Annex 1

\section{Annex 1 - Search terms}

PubMed:

(dog OR dogs OR canine OR canidae) AND (surgical treatment OR dorsal laminectomy OR dorsal decompression OR decompression OR decompressive OR distraction fusion OR Fixation Fusion OR fixation OR Fusion OR stabilization OR Foraminotomy OR Lateral Foraminotomy) AND (Degenerative lumbosacral stenosis OR lumbosacral disease OR cauda equina syndrome OR lumbosacral stenosis OR cauda equina compression)

Web of Science: (1900-present)

(dog OR dogs OR canine OR canidae) AND (surgical treatment OR dorsal laminectomy OR dorsal decompression $\mathrm{OR}$ decompression $\mathrm{OR}$ decompressive $\mathrm{OR}$ distraction fusion OR Fixation Fusion OR fixation OR 
Fusion OR stabilization OR Foraminotomy OR Lateral Foraminotomy) AND (Degenerative lumbosacral stenosis OR lumbosacral disease OR cauda equina syndrome OR lumbosacral stenosis OR cauda equina compression)

Google Scholar (1900-present)

(cão OR cães OR canídeo OR canidae) AND (síndrome de cauda equina OR doença lombossagrada OR doença lombosagrada OR estenose lombossacral OR estenose lombossagrada) AND (laminectomia OR laminectomia dorsal OR foraminotomia OR fusão OR fixação)

\section{Annex 2}

Annex 2 - Critical appraisal tool for case series assessing the results of surgical treatment for degenerative lumbosacral stenosis in the dog

1 - Were there criteria for inclusion and exclusion in the case series?

YES_ NO_ Unclear_ N Not applicable

Which criteria were used?

2 - Did the case series have consecutive inclusion of participants?
YES
NO_
Unclear
Not applicable

3 - Was there clear reporting of the demographics of the participants in the study?

YES_ NO_ Unclear_ N Not applicable__

4 - Was there clear reporting of clinical information of the participants?

YES_ NO_ Unclear__ Not applicable_

5 - Was the condition measured in a standard and reliable way for all participants included in the case series?

YES_ NO_ Unclear__ Not applicable

6 - Were valid methods used for identification of the condition for all participants included in the case series?

YES_ NO_ Unclear_ N Not applicable

Which methods were used?

7- Were the outcomes or follow-up results of cases clearly reported?
YES
NO_
Unclear
Not applicable

How were outcomes reported and measured?

8 - What was the follow-up rate of the study? 


\section{EVIIDEFaE \\ brought to you by \\ RCVS KNOWLEDGE}

\section{Intellectual Property Rights}

Authors of Knowledge Summaries submitted to RCVS Knowledge for publication will retain copyright in their work, and will be required to grant RCVS Knowledge a non-exclusive license of the rights of copyright in the materials including but not limited to the right to publish, re-

publish, transmit, sell, distribute and otherwise use the materials in all languages and all media throughout the world, and to license or permit others to do so.

\section{Disclaimer}

Any opinions expressed in articles and other publication types published in Veterinary Evidence are the author's own and

do not necessarily reflect the view of the RCVS Knowledge. Veterinary Evidence is a resource to help inform, and the content herein should not override the responsibility of the practitioner. Practitioners should also consider factors such as individual clinical expertise and judgement along with patient's circumstances and owners' values. Authors are responsible for the accuracy of the content. While the Editor and Publisher believe that all content herein are in accord with current recommendations and practice at the time of publication, they accept no legal responsibility for any errors or omissions, and make no warranty, express or implied, with respect to material contained within.

For further information please refer to our Terms of Use.

RCVS Knowledge is the independent charity associated with the Royal College of Veterinary Surgeons (RCVS). Our ambition is to become a global intermediary for evidence based veterinary knowledge by providing access to information

that is of immediate value to practicing veterinary professionals and directly contributes to evidence based clinical decision-making.

\section{https://www.veterinaryevidence.org/}

RCVS Knowledge is a registered Charity No. 230886.

Registered as a Company limited by guarantee in England and Wales No. 598443.

Registered Office: Belgravia House, 62-64 Horseferry Road, London SW1P 2AF

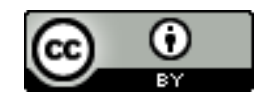

This work is licensed under a Creative Commons Attribution 4.0 International License. 